3. Lê Thị Diệu Hằng, Lại Thanh Hiên (2014). Đánh giá tác dụng điều trị thoái hóa cột sống cổ bằng mãng điên châm kết hợp bài thuốc quyên tý thang. Tạp chí nghiên cứu Y̛ dược học cổ truyền Việt Nam, 40, 54-60.

4. Nguyến Tuyết Trang, Đào Thị Phương (2016). Hiệu quả cúa phương pháp điện châm và cấy chì catgut trong điều trị đau vai gáy do thoái hóa cột sống çổ. Tapp chí nghiên cứu Y học, 103 (5), 17-23.

5. Nguyển Vinh Quốc, Nguyền Đứć Minh (2019). Hiệu quả điều trị đau cổ gáy do thoái hóa cột sống cổ bằng điện châm kết hợp bài thuốc Quyên tý thang. Tap chí Y học Việt nam, 12 (1\&2), 222-226.

6. Bô Y tế (2016). Quyết đinh số 3465/QĐ-BYT ngày $8 / 7 / 2016$ về việc ban hành bộ mã danh mục dưng chung trong khám bệnh, chữa bệnh và thanh toán bảo hiểm y tế. Phu lục: Danh mục bênh theo ICD10, Hà Nội.

7. Viến $Y$ hoc cổ truyền Quân đôi (2013). Bênh tý. Một số chuyên đề nội khoa Ỳ học cổ truyền, NXB Quân đội nhân dân, Hà Nội, 240-273.

\title{
ĐÁNH GIÁ CHẤT LƯợNG Bộ KÍT R\&D RT-qPCR HBV MộT BƯớC ĐİNH LƯỢ'NG PREGENOMIC RNA CỦA VI RÚT TRONG HUYẾT THANH BÊ̂NH NHÂN VIÊM GAN B MẠN TÍNH
}

\section{TÓM TẮT}

Muc tiêu: Đánh giá chất lương bô kit R\&D RTqPCR HBV một bước để định lượng pgRNA trong huyết thanh bệnh nhân viêm gan vi rút $B$ mạn tính. Đối tượng và phương pháp nghiên cứu: Quy trình bao gồm việc đánh giá chất chỉ tiêu chất lượng như sau: ngưỡng phát hiện, ngưỡng định lượng, khoảng tuyến tính, độ chính xác, độ đặc hiểu, độ lăp lai và so sánh khả năng định lượng với phướng pháp RT-qPCR hai bước định lượng HBV-pgRNA. Kết quả: Ngưỡng phát hiện của bộ kit là $70 \mathrm{copy} / \mathrm{ml}$ huyết thanh và ngưỡng định lượng là $140 \mathrm{copy} / \mathrm{ml}$ huyết thanh. Khoảng tuyến tính là $10^{2}-10^{8} \mathrm{copy} / \mathrm{ml}$ với hệ số hồi quy là $\mathrm{R}^{2}=0,996$. Bộ kit RT-qPCR định lượing $\mathrm{HBV}$ pgRNA có độ chính xác cao $(\mathrm{CV} \leq 0,03)$, độ lặp lại tốt (deltaCt $<0,5$ ) và độ đặc hiệu $100 \%$. Hai bộ kit có sứ tương quan cao trong định lượng HBV-pgRiNA (Hệ số tuyến tính là $\left.R^{2}=0,9885\right)$. Kết luận: bộ kit $R \& D$ RTqPCR HBV một bước có thể sử dụng trong định lượng pgRNA huyết thanh và quản lý theo dõi bệnh nhân điều trị viêm gan $B$ man tính.

Tư khóa: Pregenomic RNA,bộ kit R\&D RT-qPCR HBV một bước, viêm gan B mạn tính

\section{SUMMARY}

EVALUATE THE QUALITY OF ONE-STEP RTqPCR HBV KIT TO DETECT THE SERUM PgRNA LEVEL IN CHRONIC HBV-INFECTED PATIENTS

Objective:This study was to evaluate the quality of one-step RT-qPCR HBV kit to detect the serum pgRNA level in chronic HBV-infected patients. Materials and methods: The limit of detection, the limit of quantitation, linear range, repeatability, precision, and specificity of one-step R\&D RT-qPCR HBV kit were included in the study, as well as

*Bênh viên Quân Y 103

Chịu trách nhiệm chính: Đỗ Như Bình

Email: nhubinh.do@vmmu.edu.vn

Ngày nhận bài: 29/4/2021

Ngày phản biện khoa học: 25/5/2021

Ngày duyệt bài: 15/6/2021 compared the capability with two-step RT-qPCR method to detect serum pgRNA level. Results: The limit of detection and the limit of quantitation were 70 copies $/ \mathrm{ml}$ and 140 copies $/ \mathrm{ml}$ of serum, respectively. The linear range was from $10^{2}$ to $10^{8} \mathrm{copies} / \mathrm{ml}, \mathrm{R}^{2}=$ 0,996 . The repeatability and precision of one-step R\&D RT-qPCR HBV kit were in good performan with $\mathrm{CV} \leq 0,03$, deltaCt $<0,5$, and specificity of $100 \%$. There was a high correlation in quantification of HBVpgRNA between the two kits $\left(R^{2}=0,9885\right)$. Conclusion: The one-step R\&D RT-qPCR HBV kit could be useful for detection of serum pgRNA level and follow-up management of treated chronic HBVinfected patients.

Keywords: Pregenomic RNA; one-step R\&D RTqPCR HBV kit; CHB

\section{I. ĐĂT VẤN ĐỀ}

HBV pgRNA (pregenomic RNA) - một trung gian trong quá trình nhân lên của HBV được thấy có măt trong huyết thanh ở bênh nhân VGBMT [3]. Trong quá trình điều trị, đặc biệt là điêuu trị bằng các thuốc NA, nồng độ HBV-pgRNA huyết thanh giảm từ từ song vẫn phát hiện được kéo dài, kể cả khi HBV DNA huyết thanh đã giảm xuống dưới ngưỡng phát hiện [4], [5].

Những nghiên cứu gân đây đã chỉ ra vai trò của HBV RNA huyết thanh: phản ánh khả năng kháng vi rút của các thuốc NA; là yếu tố dư đoán sớm sự xuất hiên đột biến kháng thuốc trong quá trình điều trị bằng lamivudine; dự đoán độc lập đáp ứng vi rút học ban đâu hoặc ức chế HBV sớm hơn trong quá trình điêu trị bằng các thuốc NA; dự đoán sự tái hoạt động HBV sau khi ngừng sử dụng các thuốc NA [6]. Chính vì vậy, HBV-pgRNA huyết thanh có thể đóng vai trò quan trọng trong đánh giá, theo dõi và tối ưu hóa hiệu quả điêu trị ở bênh nhân VGBMT [4], [6], [8].

Ở Việt Nam, cho đến thời điểm hiện nay, việc định lượng HBV-pgRNA huyết thanh cũng như 
vai trò của nó chưa được nhiêu cơ sở nghiên cứu thực hiện. Đồng thời, vẫn chưa có bộ kit nào được áp dụng để định lượng HBV-pgRNA huyết thanh áp dụng trong chẩn đoán, theo dõi hiệu quả điều trị ở bệnh nhân VGBMT và xơ gan do HBV [9]. Chính vì vậy chúng tôi đã nghiên cứu phát triển 1 bộ kit R\&D RT-qPCR HBV để định lượng RNA dựa theo nguyên lý kỹ thuâtt RT-qPCR một bước. Để đảm bảo bộ kit hoạt động có hiệu quả, chúng tôi tiến hành xác định các thông sô như khoảng tuyến tính, ngưỡng phát hiện, ngưỡng định lượng, độ chính xác, độ đặc hiệu, độ lăp lại của bộ kit và so sánh đánh giá bộ kit với kỹ thuật real-time RT-PCR hai bước (phản ứng phiên mã ngược và $P C R$ được thực hiện trong hai ống phản ứng riêng rẽ) với sinh phẩm Cobas Ampliprep/Cobas Taqman HBV (Roche Diagnostics) kết hợp enzyme thương mại SuperScript III Reverse Transcriptase (Invitrogen).

\section{II. ĐỐI TƯợNG VÀ PHƯƠNG PHÁP NGHIÊN CỨU} 2.1. Đối tượng và vật liệu

- Đối tượng: Bộ kit R\&D RT-qPCR HBV định lượng pgRNA.

- Vật liệu: Các vật liệu được sử dụng trong nghiên cứu bao gồm: Chuẩn HBV được mua từ National Institute for Biological Standards and Controls (NIBSC). Các mẫu huyết thanh lâm sàng dương tính HBV nồng độ cao thu nhận từ BMK truyền nhiễm - BVQY 103 và trữ ở nhiệt độ $-70^{\circ} \mathrm{C}$ cho đến khi sử dụng. Bộ kit Cobas Ampliprep/Cobas Taqman HBV (Roche Diagnostics) kết hợp enzyme thương mại SuperScript III Reverse Transcriptase (Invitrogen).

\section{2. Địa điểm và thời gian}

- Địa điểm: Phòng vi sinh và mầm bênh sinh học - Viện nghiên cứu y dược học Quần sự Học viện Quân y và Khoa truyền nhiểm - Bệnh viện Quân y 103 - Học viện Quân y.

$$
\text { - Thời gian: 2/2021 - 5/2021. }
$$

\subsection{Phương pháp nghiên cứu}

- Xác định ngướng phát hiện (Limit of detection - LOD): hòa tan mẫu chuẩn HBV đông khô đã biết nồng độ với nước cất và pha loãng với huyết thanh âm tính HBV để tạo ra các nồng độ HBV là $10^{8}-10^{1}, 5$ và 1,25 copy/phản ứng, ở mỗi nồng độ, tiến hành phát hiện RNA của HBV lặp lại 10 lần bằng bộ kit R\&D RT-qPCR HBV-RNA;

- Xác định khoảng tuyến tính bộ kit R\&D RTqPCR HBV-pgRNA: Chuẩn HBV đã biết nồng độ được hoàn nguyên với nước cất và pha loãng với huyết thanh âm tính để tạo ra dãy nồng độ $\mathrm{HBV}$ từ $10^{2}$ đến $10^{8} \mathrm{copy} / \mathrm{ml}$. Mỗi nồng độ được định lượng 3 lần lặp lại bằng bộ kit R\&D RT-qPCR
HBV-RNA. Sau đó, xây dựng đồ thị với trục tung là trị số định lượng trung bình của 3 lần lặp lại ở mỗi nồng độ và trục hoành là nồng độ quy ước ban đầu. Đường tuyến tính và hệ số tuyến tính được xây dựng dựa trên đồ thị.

- Độ lặp lại, độ chính xác của quy trình RTqPCR: Độ lặp lại của quy trình được đánh giá qua giá trị delta $\mathrm{Ct}$ giữa các lần lặp lại ở các nồng độ khác nhau. Delta Ct càng nhỏ độ lặp lại của quy trình càng tốt. Độ chính xác của quy trình được phản ánh qua giá trị CV (Hệ số biến thiên), CV càng nhỏ độ chính xác của quy trình càng cao $(\mathrm{CV} \leq 0,05)$.

- Để xác định tính đặc hiệu trong việc định lượng pgRNA của bộ kit R\&D RT-qPCR HBV, chúng tôi thử nghiệm khả năng nhân bản chọn lọc trên nhiều loại vật liệu di truyền từ nhiều tác nhân khác nhau bao gồm RNA của virus, DNA của vi khuẩn hay gây bệnh ở người.

- Để khảo sát khả năng định lượng pgRNA của bộ kit R\&D RT-qPCR HBV trong trường hợp có chất ức chế hiện diện trong máu, chúng tổi bổ sung các chất ức chế có nguồn gốc nội sinh (hemoglobin, bilirubin, triglycerid, protein) và ngoại sinh (thuốc kháng virus, vật liệu di truyền) vào các mẩu huyết thanh dương tính HBV-RNA có nồng độ $5 \times 10^{4} \mathrm{copy} / \mathrm{ml}$. Nhóm đối chứng là cùng các mẫu huyết thanh nhưng không có chất ức chế. Sau đó, chúng tôi thực hiện định lượng HBV-RNA ở cả hai nhóm. Kết quả định lượng trong trường hợp có và không có chất cản trở được so sánh bằng thống kê paired t test (Excel).

- So sánh khả năng định lượng của bộ kit R\&D RT-qPCR HBV-pgRNA với bộ kit Cobas AmpliPrep/Cobas Taqman HBV kết hợp enzyme thương mại SuperScript III Reverse Transcriptase (Invitrogen) sử dụng phản ứng RT-qPCR hai bước. Chúng tôi định lượng HBVpgRNA trên 60 mẫu huyết thanh dương tính HBV bằng cả hai phương pháp. Hai kết quả định lượng được phân tích bằng phương pháp hồi quy tuyến tính so sánh để tìm sự tương quan.

\subsection{Phương pháp xử lý số liệu}

- Nồng độ của HBV pgRNA huyểt thanh được tính theo đơn vị copy/ml huyết thanh được tính toán bằng công thức sau:

Giá trị RNA HBV trung bình tại mỗi nồng độ được tính toán dựa theo công thức:

$$
\mathrm{C}=\mathrm{Q} * \mathrm{~V}_{\mathrm{RNA}} / \mathrm{V}_{\mathrm{PCR}} * 1 / \mathrm{V}_{\mathrm{Ext}}
$$

Trong đó, $C$ là nồng độ của trình tự đích cần tính (đơn vị là copy/ml huyết thanh), Q là số copy trình tự đích xác định được từ phản ứng Realtime PCR định lượng, $V_{\text {RNA }}$ tổng thể tích RNA thu được từ quá trình tách chiết $(\sim 50 \mu \mathrm{l}$ khi sử dụng kit 
Qiagen), VPCR là thể tích RNA tách chiết dùng cho mỗi phản ứng PCR $(6 \mu \mathrm{l})$ và Vext là thể tích huyết

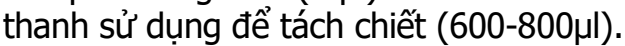

- Phân tích thông kê: Số liệu thu được sẽ được xử lí bằng phương pháp thống kê y sinh học phù hợp để xác định được khoảng định lượng, ngưỡng phát hiện, độ chính xác, độ đặc hiệu, độ lặp lại của bộ kit.

\section{KẾT QUẢ NGHIÊN CỨU VÀ BÀN LUÂ̂N}

1. Thiết kế quy trình đánh giá chất luợng bộ kit R\&D RT-qPCR HBV định lượng pgRNA huyết thanh. Quy trình đánh giá chất lượng bộ kit HBV-RNA được xây dựng dựa trên các hướng dẫn đánh giá chất lượng bộ kit hiện hành [1], [2], [7]. Quy trình bao gồm việc đánh giá chất chỉ tiêu chất lượng như sau: ngưỡng phát hiện, ngưỡng định lượng, khoảng tuyến tính, độ chính xác, độ đặc hiệu, độ lặp lại và so sánh khả năng định lượng với bộ kit ngoại nhập. Trên thực tế, các chỉ tiêu chất lượng này cũng được sử dụng để đánh giá chấtlượng của các bộ kit định lượng HBV có trên thị trường.

\section{2. Đăc tính của bộ kit onestepR\&D RT- qPCR HBV định lượng pgRNA}

2.1. Ngưỡng phát hiện, khoảng tuyến tính của quy trình phân tích. Ngưỡng phát hiện được xác định là nồng độ thấp nhất mà tại đó trên $95 \%$ tổng số lân chạy cho tín hiệu. Ngưỡng định lượng được xác định là nồng độ thấp nhất mà tại đó $100 \%$ tổng số lần chạy cho tín hiệu. Trong một lân chạy, các mẫu nồng độ được lặp lại ba lần. Tất cả nông độ đều được thực hiện đánh giá trong 10 lân chạy và ghi chép lại kết quả, tổng hợp số lần chạy cho tín hiệu khuếch đại có ý nghĩa chia tỉ lệ với tổng số phản ứng để xác định ngưỡng định lượng và ngưỡng phát hiện của bộ kit R\&D RT-qPCR HBV-pgRNA.

Bảng 1. Kết quả khảo sát ngươnng phát hiện của bộ kit R\&D RT-qPCR HBV-RNA

\begin{tabular}{|c|c|c|c|}
\hline $\begin{array}{c}\text { Nồng đồ } \\
\text { copy/phản } \\
\text { ưng }\end{array}$ & $\begin{array}{c}\text { Số } \\
\text { mấu } \\
\text { thử }\end{array}$ & $\begin{array}{c}\text { Số mấu } \\
\text { phát } \\
\text { hiện }\end{array}$ & $\begin{array}{c}\text { Phân } \\
\text { trăm } \\
\text { phát hiện }\end{array}$ \\
\hline $10^{8}$ & 30 & 30 & $100 \%$ \\
\hline $10^{7}$ & 30 & 30 & $100 \%$ \\
\hline $10^{6}$ & 30 & 30 & $100 \%$ \\
\hline $10^{5}$ & 30 & 30 & $100 \%$ \\
\hline $10^{4}$ & 30 & 30 & $100 \%$ \\
\hline $10^{3}$ & 30 & 30 & $100 \%$ \\
\hline $10^{2}$ & 30 & 30 & $100 \%$ \\
\hline $10^{1}$ & 30 & 30 & $100 \%$ \\
\hline 5 & 30 & 29 & $97 \%$ \\
\hline 2,5 & 30 & 13 & $43 \%$ \\
\hline 1,25 & 30 & 5 & $16,67 \%$ \\
\hline
\end{tabular}

Nhận xét: Ngưỡng phát hiện của bộ kit là
70 copy/ml và ngưỡng định lượng là 140 copy/ml huyết thanh.

Tiến hành tách chiết $600 \mu$ huyết thanh có nhiễm mẫu chuẩn HBV sử dụng cột silica gel và sau đó được xử lý bằng DNase I trong 30 phút. Tiếp tục tinh sạch RNA theo quy trình của QIAGEN RNeasy Mini Kit, rưa giải trong $50 \mu \mathrm{l}$. Mẫu RNA tinh sạch được pha loãng theo dãy nông độ từ $10^{1}$ đến $10^{8} \mathrm{copy} / \mathrm{ml}$, định lượng bằng RTqPCR lặp lại 3 lần. Kết quả thu được như sau:

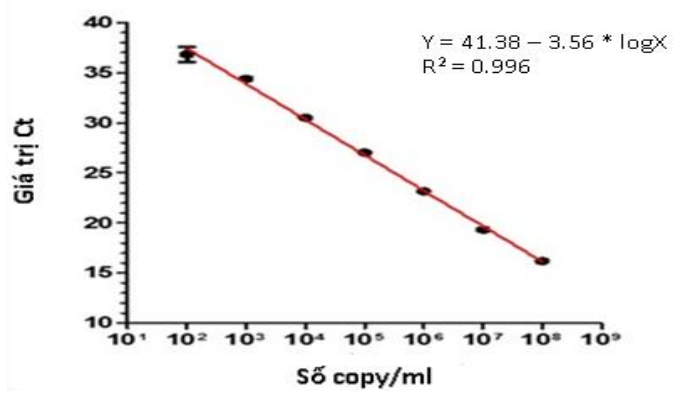

Hình 1. Đồ thị xem xét sự tuyến tính từ mẫu pha loãng $10^{2}-10^{8} \mathrm{copy} / \mathrm{ml}$

Nhận xét: Bộ kit R\&D RT-qPCR HBV-pgRNA có khoảng tuyến tính là $10^{2}-10^{8} \mathrm{copy} / \mathrm{ml}$ với hệ số hồi quy là $\mathrm{R}^{2}=0,996$.

2.2. Độ chính xác, độ lặp lại của quy trình Bảng 2. Chỉ số SD, CV của quy trinh định lương

\begin{tabular}{|c|c|c|c|c|}
\hline \multirow{2}{*}{$\begin{array}{c}\text { Mẫu } \\
\text { (phiên } \\
\text { bản/ ml }\end{array}$} & \multicolumn{2}{|c|}{ Ct } & \multicolumn{2}{|c|}{$\begin{array}{l}\text { Tải lương HBV- } \\
\text { pgRNA (Log10 } \\
\text { copies/ml) }\end{array}$} \\
\hline & CV & SD & $\mathbf{C V}$ & SD \\
\hline $10^{7}$ & 0,01 & 0,08 & 0,02 & 0,15 \\
\hline $10^{6}$ & 0,01 & 0,00 & 0,03 & 0,02 \\
\hline $10^{5}$ & 0,01 & 0,00 & 0,01 & 0,01 \\
\hline $10^{4}$ & 0,01 & 1,30 & 0,01 & 0,16 \\
\hline $10^{3}$ & 0,01 & 0,04 & 0,02 & 0,27 \\
\hline $10^{2}$ & 0,01 & 0,06 & 0,01 & 0,18 \\
\hline
\end{tabular}

Nhânn xét: Kết quả trên bảng 2 cho thấy bộ kit RT-qPCR định lượng HBV pgRNA có độ chính xác cao ( $C V \leq 0,03)$, độ lặp lại tốt (deltaCt $<0,5)$. Qữ trình tiếp tục được đánh giá trên số lượng mẫu bệnh nhân CHB lớn hơn trước khi được đưa vào sử dụng.

2.3. Độ đặc hiệu. Đánh giá mức độ phản ứng chéo với các tác nhân vi sinh vật khác, bộ sinh phẩm chỉ phát hiện HBV-RNA, không phát hiện sự hiện diện của những chủng virus (Adenovirus, Enterovirus, Sởi, Quai bị, Rubella, Influenza H1N1, Influenza H3N2, Influenza H5N1, Influenza H7N9, Influenza B, SARS CoV, Dengue Virus, Chikunkunya virus, Hepatitis C Virus, Helicobacter pylori, Herpes simplex virus, Human papilloma virus) hoặc các vi khuẩn 
$\begin{array}{lccr}\text { (Mycobacterium } & \text { intracellulare } & \text { ATCC } & 13950, \\ \text { Mycobacterium } & \text { kansaii } & \text { ATCC } & 12478, \\ \text { Mycobacterium } & \text { avium } & \text { ATCC } & 28291 \text {, } \\ \text { Mycobacterium } & \text { fortuitum } & \text { ATCC } & 6841 \text {, }\end{array}$ Mycobacterium xenopi ATCC 19250, Mycoplasma pneumoniae ATCC 15531, Mycoplasma orale, Mycoplasma genitalium, Mycobacterium tuberculosis, Bordetella pertussis ATCC 9340, Staphylococcus aureus, Streptococcus agalactiae, Streptococcus group B, Haemophilus influenza, Mycoplasma hominis, Moraxella catarrhalis, Pseudomonas aeruginosa, Acinetobacter baumannii, Klebsiella pneumoniae, Klebsiella pneumoniae, Serratia marcescens, Chlamydophila pneumoniae, Legionella pneumoniae, Bordetella parapertussis, Escherichia coli) hoặc các chất ức chế có nguồn gốc nội sinh (hemoglobin, bilirubin, triglycerid, protein) và ngoại sinh (thuốc kháng virus Interferon; Tenofovir; Lamivudine; Abarcavir; Entercavir)

Kết quả cho thây bộ kit R\&D RT-qPCR HBV chỉ nhân bản vật liệu di truyền RNA của HBV mà không nhân bản vật liệu di truyền của các tác nhân khác. Kết quả khảo sát ảnh hưởng của các chất ức chế có nguồn gốc nội sinh (hemoglobin, bilirubin, triglycerid, protein) và ngoại sinh (thuốc kháng virus) cũng không ảnh hưởng đến chất lượng bộ kit.

3. So sánh kết quả định lượng giưa hai bộ kit R\&D RT-qPCR HBV một bước và Cobas AmpliPrep/Cobas Taqman HBV kết hợp enzyme thương mại SuperScript III Reverse Transcriptase. Chúng tôi so sánh định lượng HBV trên 60 mẫu huyết thanh dương tính HBV giữa hai bộ kit onestep R\&D RT-qPCR HBV-RNA và twostep RT-qPCR HBV-RNA (Cobas AmpliPrep/Cobas Taqman HBV kết hợp enzyme thương mại SuperScript III Reverse Transcriptase). Kết quả định lượng giữa hai phép thử được so sánh bằng phướng pháp hôi quy tuyến tính.

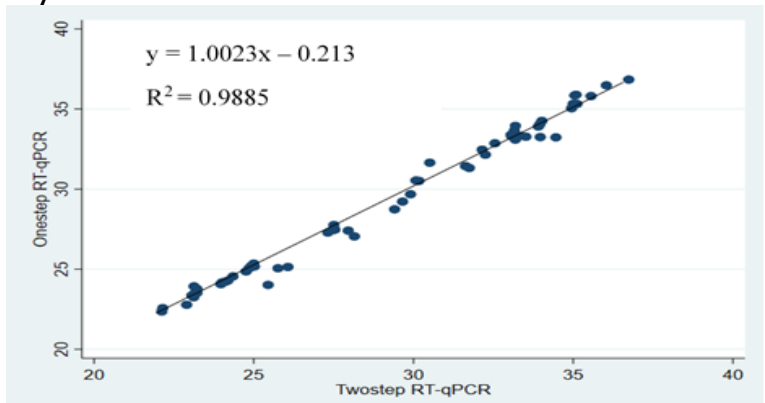

Hinh 2. So sánh tương quan giữa bộ kit R\&D RT-qPCR HBV một bước và Cobas; AmpliPrep/Cobas Taqman HBV kêt hợ enzyme

\section{thương mai SuperScript III Reverse, \\ Transcriptase định lương pgRNA}

Nhận xét: Hệ số tuyến tính là $\mathrm{R}^{2}=0,9885$ cho thấy có sự tương quan cao trong định lượng HBV giữa hai bô kit. Hệ số độ dốc (slope) của phương trình hồi quy tuyến tính là 1,0023 rất gân với giá trị 1 cho thây không có độ sai lệch tỷ lê nào trong khi hệ số chắn (intercept) là -0,213 hơi xa với giá trị 0 chỉ ra một số sai lệch hệ thống bất biến.

Kết quả so sánh giữa hai bộ kit cho thây bộ kit onestep R\&D RT-qPCR HBV-RNA có thể được sử dụng để thay thế phương pháp twostep RTqPCR HBV-RNA (Cobas AmpliPrep/Cobas Taqman HBV kết hợp enzyme thương mại SuperScript III Reverse Transcriptase) trong định lượng HBV-RNA giúp giảm được thời gian, chi phí xét nghiệm mà không bị mất đi tính hiệu quả và chính xác của phương pháp định lượng.

\section{KẾT LUÂN}

Kết quả đánh giá các chỉ tiêu chất luợng bộ kit R\&D RT-qPCR HBV trong định lượng RNA cho thấy bộ kit đạt được những chỉ tiêu sau: Ngưỡng phát hiện của bộ kit là 70 copy/ml huyết thanh và ngưỡng định lượng là $140 \mathrm{copy} / \mathrm{ml}$ huyết thanh. Khoảng tuyến tính: $10^{2}-10^{8} \mathrm{copy} / \mathrm{ml}$. Độ đặc hiệu: $100 \%$. Độ chính xác cao (CV $\leq 0,03)$, và độ lặp lại tốt (delta $\mathrm{Ct}<0,5$ ). Bộ kit có độ tương quan cao so với phương pháp realtime RT-PCR hai bước với hệ số tuyến tính là $\mathrm{R}^{2}=0,9885$, hệ số độ dốc là 1,0023 và hệ số chắn là $-0,213$ trong định lượng HBV-RNA trên các mẫu nghiên cứu.

\section{TÀI LIẸU THAM KHẢO}

1. Burd EM. 2010. Validation of laboratorydevelopedmolecular assays for infectious diseases. Clin MicrobiolRev. 23(3):550-576.

2. CLSI/NCCLS. 2003. Evaluation of precision performance of quantitative measurement methods. Approved guideline. 2nd ed. CSLI document EP5-A2. Clinical and Laboratory Standards Institute, Wayne, PA.

3. F. van Bommel, A. Bartens, A. Mysickova et al., (2015), "Serum hepatitis B virus RNA levels as an early predictor of hepatitis B envelope antigen seroconversion during treatment with polymerase inhibitors", Hepatology. 61(1), 66-76.

4. K. Giersch, L. Allweiss, T. Volz et al., (2016), "Serum HBV pgRNA as a clinical marker for ccCDNA activity", J Hepatol.

5. L. Jansen, N. A. Kootstra, K. A. van Dort et al., (2016), "Hepatitis B Virus Pregenomic RNA Is Present in Virions in Plasma and Is Associated With a Response to Pegylated Interferon Alfa-2a and Nucleos(t) ide Analogues", J Infect Dis. 213(2), 224-32.

6. M.J. van Campenhout, $F$. van Bömmel, $M$. Grossmann et al., (2017), "Serum hepatitis B 
virus RNA level is associated with hepatitis $B$ virus genotype and BCP mutations in untreated patients with $\mathrm{HBeAg}$ positive chronic hepatitis B", Journal of hepatology. 66(1), S253-S254.

7. Jennings $L$, Van Deerlin VM, Gulley ML.2009.Recommended principles and practices for validatingclinical molecular pathology tests. Arch Pathol Lab Med.133(5):743-755.

8. J. Wang, T. Shen, X. Huang et al., (2016), "Serum hepatitis B virus RNA is encapsidated pregenome RNA that may be associated with persistence of viral infection and rebound", J Hepatol. 65(4), 700-10.

\title{
NGHIÊN CỨU ĐĂC ĐIỂM LÂM SÀNG VÀ KẾT QUẢ ĐIỀU TRI BÊ̂NH THỦY ĐÂUU BẰNG ZINCPASTE TẠI PHÒNG KHÁM CHUYÊN KHOA DA LIỄU FOB CẦN THO' NĂM 2020-2021
}

\author{
Trần Ngọc Sĩ***, Huỳnh Như Huỳnh*, Nguyễn Văn Nguyên**, \\ Nguyễn Thị Thúy Liễu*, Hà Thị Thảo Mai*, Huỳnh Văn Bá*
}

\section{TÓM TẮT}

Muc tiêu: Nghiên cứu đăc điểm lâm sàng và kết quả điều trị bệnh thủy đậu bằng Zincpaste tại Phòng khám chuyền khoa Da liểu FOB Cần Thơ năm 20202021. Đối tượng và phương pháp: Phương pháp nghiên hàng loạt ca trên 60 bênh nhân mắc bênh thủy đậu điều trị ngoại trú tại Phòng khám Da liểu FOB Cân Thơ năm 2020 - 2021. Kết quả: Nhóm tuổi 20-39 tuổi thường gặp nhất $(67,24 \%)$, tỉ lệ thấp nhất là nhóm 6 tháng - 5 tuổi $(3,45 \%)$, chưa ghi nhận được nhóm $<6$ tháng tuổi và nhóm > 60 tuổi. Có tiền sử tiếp xúc với người mắc thủy đậu trước đó chiếm tỷ lệ cao $(44,83 \%)$, thấp nhất là nhóm không xác định được $(15,52 \%)$. Nhóm chưa chủng ngừa chiếm tỷ lệ cao nhất $(50 \%)$, thấp nhất là nhóm chủng ngừa không đúng $(1,72 \%)$. Triệu chứng cơ năng ngứa chiếm tỷ lể cao nhất $(75,86 \%)$. Triêu chứng toàn thân: sốt chiếm tỷ lệ cao nhất $(70,69 \%)$, kế đến là nhóm mêt mỏi $(55,17 \%)$. Thương tổn cơ bản: nhóm mụn nước, mụn nước rốn lõm chiếm tỷ lệ cao nhất $(98,28 \%)$, thấp nhất là nhóm sẹo $(1,72 \%)$. Vị trí sang thương gặp ở thân minh chiếm tỷ lệ cao nhất $(98,28 \%)$. Sau 5 ngày, có $67,24 \%$ bênh đáp ứng tốt, $32,76 \%$ đáp ứng khá. Sau 10 ngày, có $82,76 \%$ bệnh đáp ứng tốt, $17,24 \%$ đáp ứng khá. Sau 15 ngày, $100 \%$ bệnh nhân đáp ứng tốt. Số lần thoa thuốc $\geq 2$ lần cho đáp ứng điều trị tốt hơn thoa <2 lần/ngày, mối tương quan này có ý nghĩa thống kê. Qua các tuần điều trị không ghi nhận bất kì tác dụng không mong muốn nào. Kết luân: Bệnh cải thiện dần trong quá trình điều trị, người bệnh nên tuân thủ phát đồ điều trị theo bác sĩ chuyên khoa hướng dẫn để đạt kết quả tốt và tránh các biến chứng. Đáp ứng điều trị có liên quan đến số lần sử dụng thuốc bôi tại chỗ, cần tư vấn bệnh nhân sử dụng thuốc bôi $\geq 2$ lần/ngày để đạt được hiệu quả tốt nhất. Ghi nhận Zincpaste cho kểt

*Trường Đai hoc Y Dược Cần Tho **TT GD Nghể nghiêp Thẩm mỹ FOB

***Viên Thẩm mỹ Quốc Tế $A$ \&A

Chịu trách nhiệm chính: Huỳnh Văn Bá

Email: bs.ba fob@yahoo.com.vn

Ngày nhận bài: 29/4/2021

Ngày phản biên khoa hoc: 20/5/2021

Ngày duyệt bài: 18/6/2021 quả tốt trong điều trị thủy đậu, thuốc bôi tại chỗ không ghi nhận tác dụng phụ.

Tư khóa: Bệnh thủy đậu, đặc điểm lâm sàng, kết quả điều trị, Zinspate.

\section{SUMMARY \\ RESEARCH ON MANIFESTAION AND OUTCOMES OF CHICKEN POX WITH ZINCPASTE AT FOB DERMATOLOGY CLINIC IN 2020-2021}

Objectives: Studying clinical characteristics and treatment results of chickenpox with Zincpaste at FOB Can Tho Dermatology Clinic in 2020-2021. Subjects and methods: Series cases study on 60 outpatients with chickenpox at FOB Dermatology Clinic in 20202021. Results: The most common age group is 20-39 year-old group $(67,24 \%)$, the lowest rate was in the group of 6 months - 5 years old patient (3.45\%), there is no patient in the $<6$ month-old group and the $>60$ years old group. Having a history of contacting people with chickenpox previously accounted for a highest rate $(44.83 \%)$, the lowest rate was in unidentified group $(15.52 \%)$. The unvaccinated group accounted for the highest percentage $(50 \%)$, the lowest percentage was in the incorrect vaccination group (1.72\%). Symptoms of itching accounted for the highest percentage $(75.86 \%)$. Systemic symptoms: fever accounted for the highest rate $(70.69 \%)$, followed by fatigue $(55.17 \%)$. Basic lesions: the group of blisters, umbilical vesicles accounted for the highest rate $(98.28 \%)$, the lowest rate was in the scar group $(1.72 \%)$. Lesions found in the trunk accounted for the highest percentage $(98.28 \%)$. After 5 days, $67.24 \%$ of patients had excellent reponse, $32.76 \%$ had fare reponse. After 10 days, $82.76 \%$ of patients had excellent reponse, $17.24 \%$ had fare reponse. After 15 days, $100 \%$ of patients had excellent reponse. The number of times of applying the drug: patients applying it $\geq 2$ times/day gave a better treatment response than those applying it $<2$ times/day. This correlation is statistically significant. After the course of treatment with with Zincpaste gave excellent treatment results Conclusion: The severity of the disease improves gradually during the course of treatment, the patient should adhere to the treatment regimen as instructed 